Casos Clínicos

Arch. Esp. Urol., 60, 10 (1.197-1.199), 2007

\section{METÁSTASIS RENAL DE CARCINOMA EPIDERMOIDE DE PULMÓN. A PROPÓSITO DE UN CASO}

\author{
Miguel Álvarez-Múgica, Verónica Bulnes Vázquez', \\ Antonio Jalón Monzón, Roberto C. González Álvarez, \\ Jose L. Martín Benito y Jesús Mํa Fernández Gómez.
}

Servicio de Urología 1. Hospital Universitario Central de Asturias. 'Servicio de Radiodiagnóstico 1. Hospital Universitario Central de Asturias. Asturias. España.

Resumen.- OBJETIVO: Presentar un nuevo caso de metástasis renal de un carcinoma epidermoide de pulmón.

MÉTODOS: Varón de 60 años remitido a consultas externas de urología por hallazgo ecográfico de una masa renal en estudio por microhematuria.

RESULTADOS: Los estudios de imagen evidenciaron la presencia de una tumoración sólida en polo superior que se introducía hacia el seno renal, originando un atrapamiento de la arteria renal. El TC planteó el diagnóstico diferencial entre un carcinoma de células renales, un urotelioma o un proceso metastático.

Miguel Álvarez-Múgica Servicio de Urología 1. Hospital Universitario Central de Asturias. C/ Celestino Villamil s/n 33006 Oviedo. Asturias. (España) malvarez79@mixmail.com

Trabajo recibido: 2 de marzo 2007
CONCLUSIONES: El cáncer de pulmón puede producir metástasis en cualquier órgano, pero el riñón no es uno de los órganos de asentamiento más frecuentes, sin embargo, la existencia de dos o más metástasis extratorácicas confieren un pobre pronóstico a esta patología.

Palabras clave: Metástasis renal. Carcinoma epidermoide de pulmón.

Summary.- OBJECTIVE: To report a new case of renal metastasis from an squamous cell carcinoma of the lung.

METHODS: A 60 year old male presented to the outpatient office with an ultrasound finding of renal mass.

RESULTS: Imaging test studies showed a heterogeneous mass in the upper pole of the left kidney, involving the pelvis and trapping the renal artery.

CONCLUSIONS: Clinically recognised or symptomatic metastases to the kidney from pulmonary cancer have been a rare occurrence. Nevertheless, prognosis associated with lung carcinoma metastatic to the kidney is very poor, since the likelihood of a truly solitary metastasis is remote.

Keywords: Renal metastases. Squamous cell carcinoma of the lung.

\section{INTRODUCCIÓN}

El carcinoma de pulmón es una entidad con capacidad de producir metástasis en cualquier órgano, pero las localizaciones más frecuentes y clínicamente manifiestas son: pulmón, pleura, hueso, cerebro, pericardio e hígado (1).

Las metástasis renales de los carcinomas de pulmón son sin embargo una entidad poco frecuente desde el punto de vista sintomático, siendo descubiertas en la mayor parte de los casos en exámenes de autopsia sobre todo, o bien en estudios de imagen en pacientes asintomáti$\cos (2)$.

Las referencias bibliográficas de esta entidad son escasas, y además en la mayor parte de casos el diagnóstico no modifica significativamente la actitud terapéutica del paciente.

\section{CASO CLÍNICO}

Se trata de un varón de 60 años, que consultó por haber presentado varios episodios de hematuria total, sin síndrome miccional ni otra clínica asociada. Como antecedentes destacaba haber sido tratado 2 años antes de un 
carcinoma epidermoide de pulmón en lóbulo superior izquierdo, realizándosele una neumectomía izquierda y linfadenectomía hiliar y mediastínica, siendo el estadiaje (T2N1MO), recibiendo radioterapia adyuvante.

A la exploración se evidenció una moderada palidez mucocutánea. El abdomen era blando sin signos de dolor a la palpación, no palpándose masas ni megalias.

El hemograma, bioquímica y coagulación resultaron normales.

La ecografía, evidenció una alteración en la ecoestructura y ecogenicidad del polo superior del riñón izquierdo (Figura 1). El resto de la exploración abdominal resultó normal.

El TC mostró la presencia de una masa heterogénea de $6,2 \times 3,2 \mathrm{~cm}$ ocupando el tercio medio y superior del riñón izquierdo (Figura 2), introduciéndose en el seno renal y produciendo atrapamiento de la arteria renal izquierda (Figura 3).

La imagen aunque sugerente de carcinoma, planteó dudas sobre un posible origen urotelial o metastático. No se apreciaron adenopatías. Esta imagen no se había apreciado en el TC de control realizado 4 meses antes.

La gammagrafía ósea descartó la presencia de hallazgos patológicos a nivel óseo. Las citologías de orina resultaron negativas siendo el sedimento de orina normal.

Con estos hallazgos y ante la sospecha de carcinoma renal vs. urotelioma vs. metástasis, se decidió la realización de una nefrectomía radical izquierda, observándo-

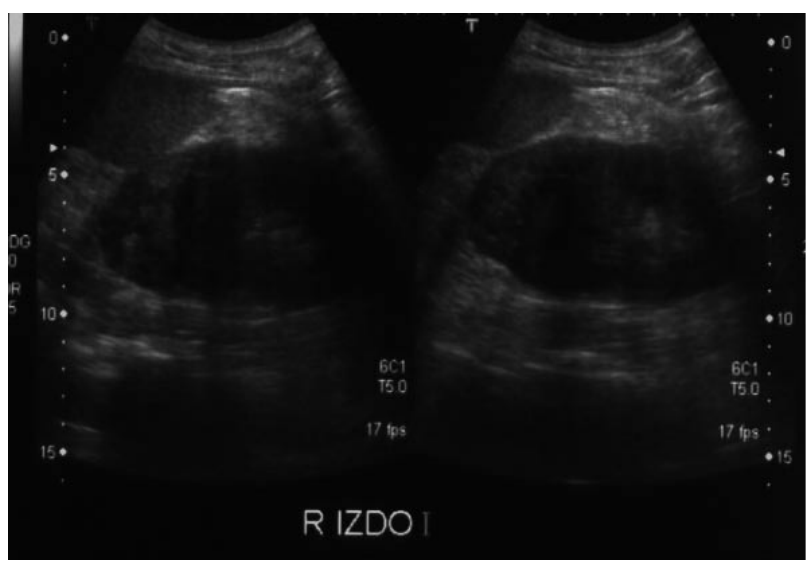

FIGURA 1. Ecografía: alteración en la ecoestructura y ecogenicidad en el polo superior del riñón izquierdo. se infiltración tumoral de la vena renal y de la arteria renal, así como una importante reacción inflamatoria perirenal. La anatomía patológica evidenció una neoformación epitelial atípica con diferenciación escamosa infiltrando el parénquima renal y la grasa perirenal y con invasión de paredes vasculares. El análisis inmunohistoquímico confirmó el diagnóstico de metástasis de carcinoma epidermoide.

\section{DISCUSIÓN}

El carcinoma de pulmón puede producir metástasis en cualquier órgano, siendo las localizaciones más frecuentes el pulmón, la pleura, el hueso, el cerebro, el pericardio y el hígado $(1,3)$.

La neoplasia sólida que más frecuentemente metastatiza en el riñón es el cáncer de pulmón, de los cuales entre el $30 \%$ y el $60 \%$ según las series, son de localización bilateral (4).

Las molestias que presenta el paciente con diseminación metastásica están determinadas por la ubicación específica del órgano afectado. Las metástasis renales de los carcinomas de pulmón son relativamente infrecuentes, siendo además asintomáticas por lo que el diagnóstico de las mismas se produce en la mayoría de los casos mediante técnicas de imagen o en las autopsias (4), si bien, gracias al mayor uso del scanner durante el control postoperatorio de los mismos, ha originado un aumento de diagnósticos ante mortem (5).

Si a esto se añade el aumento de la supervivencia de estos enfermos gracias al uso del tratamiento quimioterápico adyuvante, los procesos metastáticos renales,

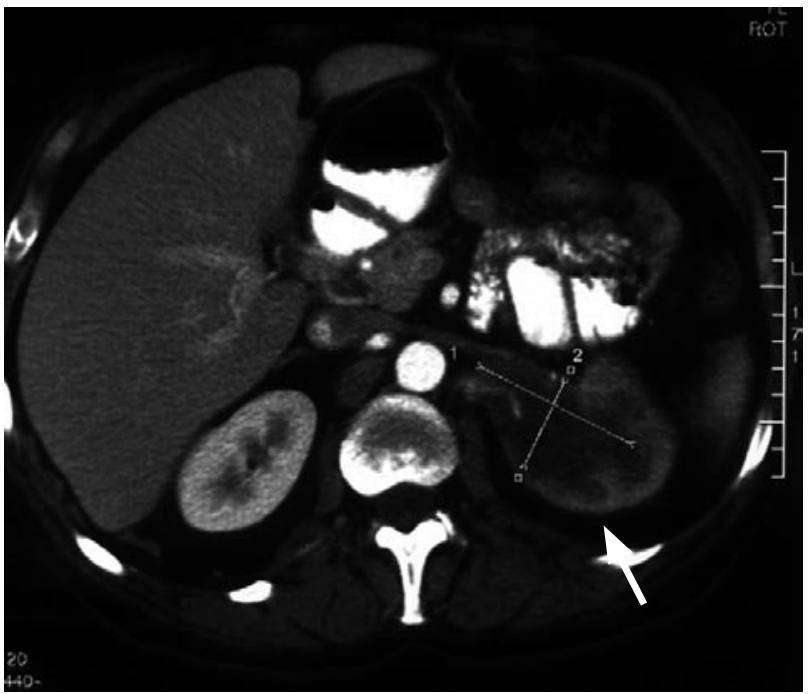

FIGURA 2. TC: masa heterogenea de 6,2 $\times 3,2 \mathrm{~cm}$ ocupando el tercio medio y superior del riñón izquierdo. 


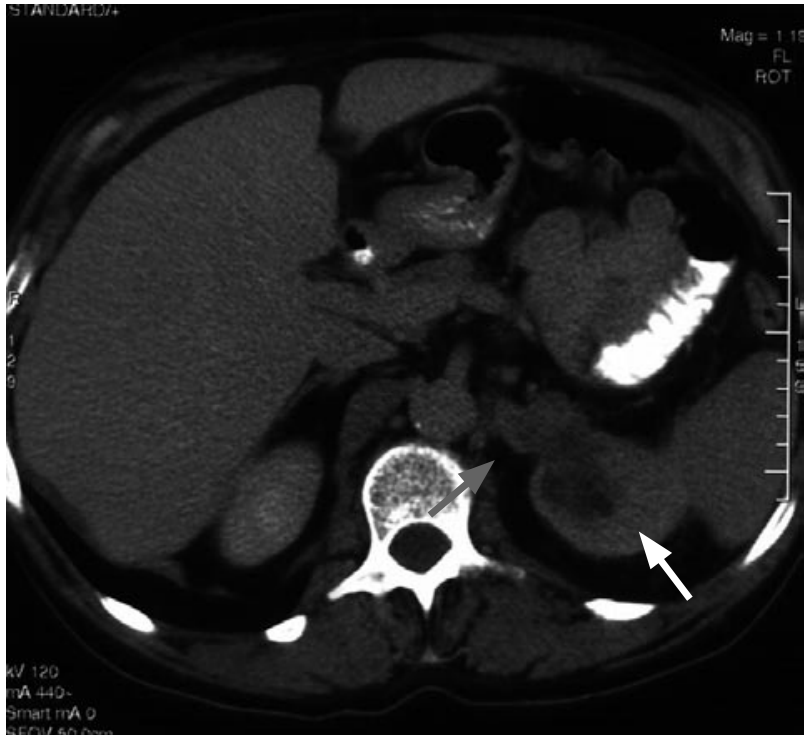

FIGURA 3. TC: masa introduciéndose en el seno renal y produciendo atrapamiento de la arteria renal izquierda.

han convertido en verdaderos problemas clínicos lo que antes eran hallazgos subclínicos (2).

En la serie de la Eastern Virginia Medical School se encontraron metástasis renales hasta en el $19 \%$ de los enfermos que murieron tras ser diagnosticados de un cáncer de pulmon (2).

Olsson y cols. describen que un $80 \%$ de los pacientes que presentaban metástasis renal de su serie cursaban de forma asintomático, un $12 \%$ con hematuria y un 5 $\%$ con dolor en flanco en una extensa serie de autopsias realizadas en el Boston Veterans Administration Hospital entre 1959 y 1968 (6). Klinger, justifica el bajo porcentaje de estos pacientes con hematuria en que la mucosa pielocalicial no se ulcera con tanta frecuencia en las neoplasias renales secundarias (4).

El pronóstico de estos enfermos es muy malo, ya que la existencia de dos o más metástasis extratorácicas tiene un peor pronóstico de supervivencia (7), así, la tasa de fallecimientos es mayor del $75 \%$ al año del diagnóstico (6), y todo ello dependerá de la eficacia del tratamiento sobre el tumor primario y la resecabilidad del tumor secundario, sólo posible en casos unilaterales y solitarios (4).

\section{CONCLUSIONES}

Los procesos metastáticos renales secundarios a un carcinoma primario pulmonar afecta según las series hasta un $19 \%$ de los enfermos. Este dato es importante, ya que las mejorías de los índices de supervivencia de estos enfermos, pueden convertir en verdaderos problemas clínicos lo que antes eran meros hallazgos patológicos. Para el diagnóstico de estos enfermos debería incluirse el TC renal y la urografía endovenosa.

El pronóstico de este tipo de enfermos, es aún muy pobre, falleciendo más del $75 \%$ en el primer año tras el diagnóstico.

\section{BIBLIOGRAFIA y LECTURAS RECOMENDADAS ( ${ }^{*}$ lectura de interés $y^{* *}$ lectura fundamental)}

1. ROSELL, R.; MAESTRE, J.; MOLINA, F.: "Cáncer de pulmón de célula no pequeña”. Oncol Med. Rosell R, Abad A, Monzo M, Molina F. Ediciones Ergón, pág. 153-66, Madrid, 1995.

2. BECKER, W.E.; SCHELLHAMMER, P.F.: "Renal metastases from carcinoma of the lung". BJU, 58: 494, 1986.

3. GINSBERG, R.J.; VOKES, E.E.; RABEN, A.: "Cáncer de pulmón de célula no pequeña. Manifestaciones metastáticos”. Cáncer, principios y práctica de Oncología. De Vita Jr. VT, Hellman S, Roosemberg SA. Ed. Panamericana. ARAN, 868, Madrid, 2000.

4. OLSSON, C.A.; MOYER, J.D.; LAFERTE, R,O.: "Pulmonary cancer metastasic to the kidney a common renal neoplasm”. J. Urol., 105: 492, 1971.

5. KWAK, T.I.; KIM, D.S.; KIM, J.J.: "Lung cancer metastasizing to ipsilateral renal cell carcinoma and the contralateral perirenal space". BJU International, 83: $512,1999$.

6. O'CONNELL, J.; KRIS, M.; GRALLA, R.: "Frequency and prognostic importance of pretreatment clinical characteristics in patients with advanced non-small cell lung cancer treated with combination chemotherapy". J. Clin. Oncol., 4: 1604, 1996.

7. RAVICH, L.; LERMAN, P.H.; DRABKIN, J.W.: "Metastasic disease to kidney from lung". Urol., 5: 239, 1975. 